\title{
SINT MAARTEN, SINT EUSTATIUS EN SABA \\ DOOR
}

MR. B. DE GAAY FORTMAN.

In De West-Indische Gids van October 1919 bladz. 471 e. v. deelt F. E. baron Mulert mee, wat Charles de Rochefort, Histoire Naturelle et morale des Isles Antilles vertelt van De Nederlandsche Bovenwindsche eilanden in het midden der I7de eeuw. Het is niet onvermakelijk wat Père Labat in zijn Nieuwe Reizen naar de Franse eilanden van America (vertaling van W. C. Dijks, Amsterdam 1725) over dezen schrijver meedeelt. „De Predikant Rochefort”, zegt hij, ,die de Amerikaanse Eilanden niet dan met de oogen van een ander gezien heeft, heeft nogtans niet nagelaten daar van eene Historie, die in 't jaar 1659 in Holland in 4. gedrukt is, in 't ligt te geven, dewelke verdraagelijk genoeg zoude zijn, om dat hij ze uit het Werk van den Vader $d u$ Tertre na geschreeven heeft, maar hij heeft zijn Verhaal teneenemaal bedorven door zijne beschrijvingen, die teneenemaal tegens de waarheit aenlopen, met oogmerk, om de zaken aangenamer te maken, en zijnen roof des te beeter te bedekken."

De beschuldiging is ernstig genoeg om haar te onderzoeken.

In de aanteekening van den heer Mulert is reeds eraan herinnerd, dat De Rochefort tot 1650 predikant was op de door de Lampsins gekoloniseerde Bovenwindsche eilanden ${ }^{1}$ ). De eerste beschuldiging, dat deze schrijver

1) Hamelberg, Documenten behoorende bij „De Nederlanders op de West-Indische eilanden" II bladz. 16 deelt het octrooi mee, verleend aan de gebroeders Adriaan en Cornelis Lampsins, voor de kolonie Tobago. Daarbij was hun de verplichting opgelegd ook de geestelijke behoeften 


\section{SINT MAARTEN, SINT EUSTATIUS EN SABA.}

slechts „met de oogen van een ander” de Amerikaansche eilanden gezien heeft, is dus in hare algemeenheid zeker niet juist. Maar ook de tweede beschuldiging, die van Père $\mathrm{Du}$ Tertre nageschreven te hebben, kan niet volgehouden worden.

Het werk van Du Tertre, hier bedoeld, Histoire generale de l'establissement des colonies françoises dans les Ant-Isles de l'Amerique is verschenen te Parijs in 1667-1671. Labat geeft ten onrechte op als datum van uitgave 1658. En De Rocheforts Histoire dateert in eersten druk van 1658 (Labat meent 1659), de tweede druk van 1665, terwijl daar tusschen ligt de Hollandsche vertaling van 1662 .

Er is echter nog meer.

De Rochefort geeft een verhaal van de deeling van Sint Maarten door de Hollanders en Franschen, dat afwijkt van de mededeelingen van Du Tertre, welke laatste ook door Hamelberg voor gezaghebbend gehouden worden, gestaafd als zij zijn door documenten, die het stempel dragen van authenticiteit. Heeft de heer Mulert ons het verhaal van De Rochefort meegedeeld, de uitvoerige beschrijving van Du Tertre is te vinden bij Hamelberg, Documenten enz. II bladz. $24 \mathrm{e}$ v. en in vertaling bij denzelfde De Nederlanders op de West-Indische eilanden II De bovenwindsche Eilanden St. Eustatius, Saba, St. Martin bladz. I4 e.v. ${ }^{1}$ ) Wij mogen deze beschrijving als bekend veronderstellen, in ieder geval is het hier niet de plaats, haar nog eens

der kolonisten te verzorgen, en daartoe de kolonie ,,te voorsien van een sieckentrooster ende voorleser, op dat den Godts dienst aldaer mach werden gepleeght ende de coloniers op den Sabbathdach bij een comen om te singen, ende een sermoen te lesen, op poene van te vervallen in de straffe daertoe te stellen".

De Rochefort was na zijn terugkeer tot 1653 Waalsch predikant te Vlissingen en daarna tot 1682 te Rotterdam. Zie Biographisch Woordenboek van Nederlandsche godgeleerden door B. Glasius, 's-Hertogenbosch 1856.

1) Du Tertre t. a. p. dl. I bladz. 408 e. v. Men zie ook van Hamelberg, Historische schets van de Nederlandsche Bovenwindsche antillen tot op het einde der I je eeuw op bladz. $111 \mathrm{e} . \mathrm{v}$. in het Tweede Jaarlijksch Verslag van het Geschied-, Taal-, Land-en Volkenkundig Genootschap te Willemstad. 
SINT MAARTEN, SINT EUSTATIUS EN SABA. 215

te herhalen. Opmerkelijk is het, dat hetgeen Labat in deel IV 2e stuk bladz. 126 e. v. verhaalt, geheel overeenkomt met de geschiedenis, zooals Du Tertre die beschrijft, zoodat althans hier De Rochefort in originaliteit zijnen beschuldiger schijnt te overtreffen.

Wat de deur dicht doet is echter hetgeen Du Tertre aan het slot van zijn verhaal meedeelt. Men leest daar: L'on peut juger de ce que ie viens de dire, \& des pieces que j'ay rapportées de la fidelité des memoires du sieur de Rochefort, qui dans la page 59 de la seconde Edition de son Livre, nous veut persuader que l'habitation de cette Isle faite par les Hollandois fut un cas fortuit, et que ce fut par hazard que M. Rüyter côtoyant les costes de cette Isle, apperceut que les Espagnols l'avoient abandonnée; car bien qu'il soit vray que M. Rüyter y porta les hommes destinez par le Gouverneur de Saint Eustache pour l'habiter, il n'est pas vray pourtant, ny qu'il ait levé ces hommes, ny qu'il en ait pris possession pour Messieurs les Estats-Generaux des Provinces unies, comme il est aisé de juger par la Commission donnée par le Gouverneur de Saint Eustache au sieur Martin Thomas, rapportées cy-dessus, et par les articles passez entre luy et $M$. de Lonvilliers, qui partagerent l'Isle, non pas depuis comme il l'écrit au mesme endroit, mais dans le mesme temps que les Francois en prirent possession."

Du Tertre heeft dus den tweeden druk van De Rocheforts werk gekend, zoodat het uitgesloten is, dat De Rochefort Du Tertre nageschreven kan hebben. En de beschuldiging van Labat is onjuist.

Desalniettemin is het wel belangwekkend naast hetgeen De Rochefort meedeelt, nog eens af te drukken wat Labat een zestig jaar later van onze Bovenwindsche eilanden wist te verhalen.

Vooreerst dit - dat het verdrag, op 23 Maart 1648 op St. Maarten tusschen de Hollanders en Franschen gesloten op den top van den berg Concordia, een defensief verbond, in 1702 opnieuw bevestigd werd ${ }^{\mathbf{1}}$ ):

${ }^{1)}$ Labat, t. a. p. IV 2e st. bladz. 130. 
„zo dat, wanneer een Fransche kaper, of een andere, daar komt om te handelen, hij er wel ontfangen word, en zynen handel met de grootste veiligheit dryft: maar indien hy de Hollanders moejelykheden wil aandoen, nemen de Franschen ten voordeele van haar de Wapenen op, en verdeedigen dezelve. De Hollanders doen 't selfde voor de Franschen, wanneer de Vaartuigen van haare Natie of de Engelschen niet willen blyven binnen de paalen van 't Concordaat, dat tusschen de twee Natien is ${ }^{\mathbf{1}}$."

In 1705 heeft Labat het Fransche gedeelte van het eiland St. Maarten bezocht, en toen ook een uitstapje op het Hollandsch gebied gedaan, waarvan hij verhaalt: „Na het uitgaan van de Kerk gingen wy een Visite geven aan den Hollandschen Commandant; deze had zo veel gezag niet als de onze, alzoo hy geen $D o c$ $\left.t_{o r}{ }^{2}\right)$ was, en een Predikant by sig had; hy ontfing ons zeer heus, en onze complimenten wierden door tolken verrigt, tot dat ik wist, dat hy de Latynse Taal beter verstond dan onze Schoolmeester; toen spraaken wy zelfs met elkander; hy sprak weinig om dat hy veel en dikwils dronk; en hy deed ons Bier, Wyn van Madera ponche en zoete koek geeven ${ }^{3}$ )."

Sint Eustatius heeft de schrijver alleen vanaf de reede gezien. Hij zegt ervan: „Het zelve vertoont zig als twee Bergen, die van elkander gescheiden zijn door een groote Vallei, waar van de vlakte ruim tien Roeden boven 't Strand verheven is. De Berg van de West zijde is verdeelt in twee of drie hoofden, met Boomen bedekt, en zyne afhelling schynt niet zeer moeijelijk te zijn. De Berg aan de Oostzyde zoude veel hooger zyn dan de eerste, indien hy geheel was; Maar hy schynt op twee derde van zijn hoogte, die hy eigentlijk zou moeten hebben, afgesneeden te zyn. Hy vertoont zig

1) Labat, t. a. p. IV 1e st. bladz. 46. Men vindt het verdrag bij Hamelberg, Documenten, blazd. 30/2. Art. VII luidt: „Que s'il arrive des ennemis pour attaquez l'un au l'autre quartier lesdits sieurs Concordants s'obligent à s'entre-aider \& prêter secours l'un à l'autre".

$\left.{ }^{2}\right)$ De Fransche commandant was tegelijk pastoor, rechter en dokter.

3) Labat, t. a. p. IV 2e st. bladz. 132. 
byna als de form van een Hoed, die men een weinig ingedrukt heeft. Dit Eiland quam ons zeer fraai en wel bebouwt voor: Het Fort schijnt aan den voet van den Berg te leggen, hoewel 't nog op een aanzienlyke distantie daar van zijn moet, die ik van de plaats, alwaar ik my bevond, niet konde zien. De Franschen zijn 'er twee-of driemaal Meester van geweest. Daar is tusschen St. Eustache, en 't eiland St. Christoffel, maar een Kanaal van drie mylen breed $\left.{ }^{1}\right)$."

Zeer uitvoerig is het verslag van een bezoek aan Saba op 27 April 1701: „Dit Eiland is nog kleiner, als dat van St. Thomas, en vertoont zig maar als een steenrotz van vier of vijf mylen in 't rond, aan alle kanten ongenaakbaar. Men kan daar niet aan Land treeden, dan op een kleine zandbaai, ten Zuiden geleegen, waar op de Inwoonders hunne Canots trekken. Een weg, kruiselings in de Rotz gehouwen, geleid op den top van 't Eiland, alwaar 't terrein evenwel effen, goed en vrugtbaar is. Ik geloof, dat de eerste, die daar geland zyn, Ladders hebben gebruikt, om daar op te klimmen. Het is een natuurlijke Fortres, en ten eenemaal onoverwinnelijk, indien men geen gebrek aan leeftogt heeft. De Inwoonders hebben op verscheide plaatsen van dezen weg steenhoopen vergadert, en gelegt op planken, die op houte paalen zodaanig rusten, dat men, aan een koorde trekkende, alle deze steenen doet vallen, om, zonder medogentheit, een gantsche Armee te verpletteren, indien ze daar, of op eenige plaatsen van de Baai, wilde opklimmen. Men zegt, dat er op de Noordoost-zyde een andere plaats is, die men ligtelyker kan beklimmen, dan deze, die ten Zuidwesten legt: vooronderstelt zynde dat men daar kan landen: maar de Zee is daar gemeenlyk zo onstuimig dat men daar by de Kust niet kan komen, en dit is de oorzaak, waarom de Inwoonders die plaats niet ontoegankelyk hebben gemaakt, alzo zy van die kant niets te vreezen hebben.

1) id. IV 2e st. bladz. 50. 
De Commandant of Gouverneur van dat Eiland quam aan ons boord, na dat onze Canot aan Land was geweest, en men ons wel gekent had. Want, hoewel wy in vreede waren, vreezen zy egter, met reden, 't bezoek der zeerovers. Hy noodigde ons op 't middagmaal, waar over ik zeer verblyd was, alzo ik 't Eiland gaarn bezigtigen wilde. Wy klommen dan op, en waren met aangenaamheit verwondert van een zeer fraai Landschap, boven 't geen ons niet anders dan een vreesselijke steenrotz gescheenen had, te vinden. Men zeide ons, dat 't Eiland in twee quartieren verdeelt was, en dat daar in veertig of vyftig familien waren: De Wooningen zyn daar zeer net en wel onderhouden. De Huizen zyn vermaakelyk, gemakkelyk, wel gewit, en wel gemeubileert. De voornaamste Handel van dit Eiland bestaat in schoenen, en ik heb nooit een land gezien, waar in zo veele Schoenmaakers waren. De Gouverneur bemoeit zig daar mede gelyk als de andere, en ik geloof, dat de Predikant zig met deze adelyke oeffening op zyn ledige uuren vermaakt. Het is jammer, dat dit Eiland aan geen Catholyke Schoenmaakers behoort, want zy zouden 't zeeker met meer reeden 't Eiland van St. Crispinus noemen, dan 't Eiland Saba, 't geen wij niet leezen, een Koninkrijk van Schoenmaakers te zijn geweest. Hoe 't ook daar meê zij, wij wierden 'er wel ontfangen. De Inwoonders leven 'er in goede eenigheit; Zij eeten dikwils bij elkander: zij hebben geene Vleeschhallen, als men in de andere groote Eilanden heeft: Maar zij dooden, de een na den ander, zo vele Beesten, als 'er voor 't geheele quartier noodig zijn, zonder iets te betaalen. Zij neemen 't Vleesch, dat zij voor hunne familien noodig hebben, bij den geenen, die zijn Beest geslacht heeft, en zij betaalen 't met de zelve munt, als 't haar beurt is om hunne Beesten te dooden. De Commandant maakt daarmede een begin, en de andere van 't quartier volgen hem, tot dat het wederom zijne beurt is.

Daar waren onder hen eenige Fransche Vlugtelingen, die mij veel beleeftheid toonden. Ik sliep aan Land, na 
den geheelen agtermiddag met wandelen doorgebragt te hebben. Mijn gewaad deed haar wat verbaast staan, en zy waren verblyd, dat ik in hunne Huizen intrad, opdat zy 't op haar gemak bezien konden. Ik kogt zes paar schoenen, die zeer goed waren. Wy verkogten aan haar een gedeelte van de groene Huiden, dat is te zeggen, die nog niet bereid zyn welke wy op het KoeiEiland ingenomen hadden: Hoewel zij geen andere Commercie dryven, dan met haare schoenen, en een weinig katoen en Indigo, zyn ze egter ryk, en hebben slaven, zilverwerk en goede meubilen.

De Heer Pinel, een van onze kapers, dagt de Inw'oonders van dit Eiland geduurende den Oorlog van 't jaar 1688 , te verrassen. Hy had een Bark, die op haare rekening geladen was, genomen, en quam daar mede met een groot gedeelte van zijn volk in 't begin van de nagt aan Land, en vermits de Inwoonders dezelve te gemoet zagen, en kenden, hadden zy 'er geen quaad vermoeden op. Ons volk begon reets op te klimmen wanneer de Bark, waar mede zy ter Kaap voeren, en die ordre had om niet te komen dan na dat men aan dezelve het zein, door 't aanstooken van een vuur op 't Eiland, gegeeven had, verhaaste zich te zeer, en quam mede aanzeilen, om ter zyde van de eerste te ankeren. Die, welke daar in waren, dezelve voor een vyandlyk Vaartuig aanziende, schooten daar op, en deze van gelyke gedachten zynde, maakten van hun kant ins gelijks vuur op hen, doodden een man, en quetsten drie of vier andere, daar onder den kapitein. De Inwoonders greepen terstont na de Waapenen, en, aan den aanslag twyffelende, of om zig in een grooter veiligheit te stellen, deeden zy een hagelbui van steenen op onze luiden, die bezig waren met op te klimmen, regenen; waar door sommige verminkt, en de andere genootsaakt wierden, zig met 'er haast weg, en na haare Bark te begeeven, zynde 't niet mogelyk iets verder re onderneemen. De nacht, die zeer duister was, had onze luiden in 't begin begunstigt. Maar die was ook naderhand oorzaak, dat zy door hunne mak- 
kers niet gekent wierden, en de onderneeming mislukte. Het is zeeker, dat ze een fraaie buit daar van daan zouden gehaalt hebben.

Den 28 vertrokken wy na 't ontbyt alvorens te hebben genomen. De Commandant vereerde ons een lang gebraade Nierstuk van een Kalf, met ruim twintig pond ongekookt Vleesch, Bananassen, en zeer fraaie appelen van Acajou"'1).

1) Labat, t. a. p. IV 2e st. bladz. 46 e. v. 